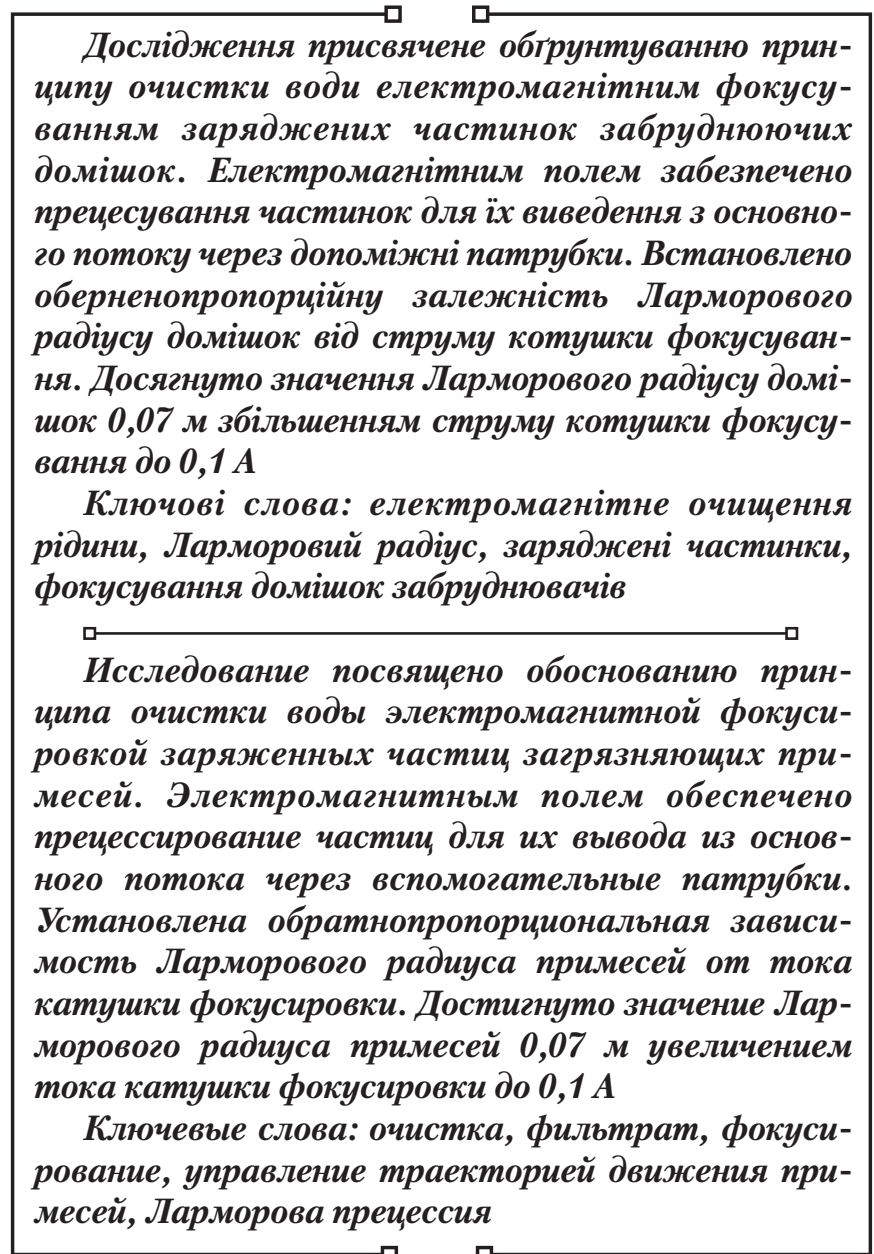

UDC 537.6 .612

DOI: $10.15587 / 1729-4061.2016 .75251$

\title{
ELECTROMAGNETIC FOCUSING OF IMPURITIES IN WATER PURIFICATION
}

\author{
O. Terentie v \\ Doctor of Technical Sciences, Professor* \\ E-mail: oltr_1@ukr.net \\ K. T $\bar{k}$ achuk \\ Doctor of Technical Sciences, Professor** \\ E-mail: k.tkachuk@kpi.ua \\ O. T verd a \\ PhD, Senior Lecture** \\ E-mail: o.tverda@kpi.ua \\ A. KI esh chov \\ Postgraduate Student* \\ E-mail: anton.kleshchov@gmail.com \\ *Electromechanical equipment of \\ energy-intensive industries department $* * *$ \\ **Environmental Engineering Department*** \\ $* * *$ National Technical University of Ukraine \\ "Kyiv Polytechnic Institute" \\ Peremohy ave., 37, Kyiv, Ukraine, 03056
}

\section{Introduction}

The accumulation of household waste in the places of its storage leads to emitting a liquid filtrate. Its treatment before mixing with sewage is a topical technical problem. The filtrate that is formed during the household waste storage is subject to treatment to meet the DSTU EN 1420-1:2004 standards. The purified liquid quality is regulated by international and European standards, such as ISO 17381:2003; National Archives, London, UK; "The Water Supply (Water Quality) Regulations 2000"; U.S. Clean Water Act, Section 303, and others. Therefore, it is necessary to develop a method of purifying aqueous media that would be based on the control of the trajectory of impurities for their subsequent removal from the flow. In this case, the purified liquid quality can meet the requirements of the international standards.

\section{Literature review and problem statement}

Study [1] is devoted to the treatment of filtrates when garbage is stored or buried. The author analyzes the existing methods of wastewater treatment and concludes that the most effective one is the Reverse Osmosis. A disadvantage of this method is that it does not allow demineralizing and removing volatile organics and chlorine. The authors of study [2] propose using the Phyllanthus emblicawood. This method results in the following:
- reduced contents of $\mathrm{pH}$, sulfates, magnesium, colon bacillus, total coliforms, and faecal coliforms (which is an advantage of the proposed method);

- increased turbidity, conductivity, higher contents of calcium, iron and chloride ions, as well as nitrate level (which is a drawback of the method).

Study [3] focuses on water purification by means of magnetic separation. An advantage of this method is ensuring both water purification and removal of the impurities that adhere to inner walls of the pipes. A disadvantage is the lack of control of the contaminants' trajectory for their subsequent removal from the main flow.

In [4], there is considered the use of an electromagnetic field in the removal of salt from liquid media. It is found that when an electromagnetic field affects a liquid flow, calcium carbonate sediment becomes less dense than without the use of an electromagnetic field. The electromagnetic field was created by an alternating current of $25 \mathrm{~A}, 50 \mathrm{~Hz}$, which allowed increasing the load on power cables. However, a long-term operation in this mode leads to risky situations and an increase of penalties.

Study [5] suggests using a pulsating field to saturate the liquid with positively charged oxygen ions, which contributes to disinfection of liquids. The authors propose using a generator with the frequency variation system, which is possible due to varying the number of turns in the induction coil. A disadvantage is the lack of variation in the operational mode when the content of impurities in the flow changes.

The authors of [6] propose an electromagnetic hydrocyclone separator for separating water and contaminated sedi- 
ments. The researchers use electromagnetic forces to affect the structure of water. The downside is independence of the system parameters from the chemical composition of the contaminants.

Study [7] focuses on the effect of heavy metal ions on plants (Lemna minor) under the influence of electromagnetic radiation of quasi-high frequencies. It was found that electromagnetic radiation increases the survival of plants in a medium with heavy metals, stimulating the plants' growth and the cells' capacity to absorb toxicants. The most effective was radiation at frequencies of $60 \mathrm{GHz}$ and $145 \mathrm{GHz}$ when the energy flux density was $120 \mu \mathrm{W} / \mathrm{cm}^{2}$. The found effect is proposed to improve water treatment. Disadvantages include the need of a direct contact of flora with the liquid, which negatively affects the bacterial background of water.

The findings of [8] indicate that water purified with an electromagnetic field can have a variety of biological effects on the plant cells. They are associated with the "water memory effect". Therefore, it is necessary to study further the mechanisms of physical fields' effect on aqueous media. A disadvantage of the above water purification methods is the lack of a direct impact on the contaminants. The electromagnetic purification systems interact with the liquid rather than its contaminants.

A common shortcoming of the above considered studies is a direct effect of the purification systems on the liquid. The suggested study focuses on the direct effect of electromagnetic fields on the contaminants and their removal from the main flow.

\section{The purpose and objectives of the study}

The aim of the study is to substantiate the principle of removing impurities' ions from water by focusing them by means of an electromagnetic field in the auxiliary drain tube.

To achieve this goal, we set the following tasks:

- to prove the dependence of the Larmor radius of contaminants' mechanical trajectory on the focusing coil current for a rational placing of the impurities' drain tubes;

- to choose the tubes' diameter by the minimum Larmor radius of focusing the impurities to remove them from the main flow;

- to control the impurities' mechanical trajectory by means of an electromagnetic device that ensures the Larmor precession and, thereby, helps to remove the focused impurities from the main flow.

\section{Materials and methods of research on the effect of an electromagnetic field on the charged particles of impurities}

The research consists in the simulation of the process of focusing impurities (e. g. nitrates) in the flow by means of an electromagnetic field. The process is simulated in LabView that is a source programming system and has a built-in support of all the currently used programming interfaces.

The computer simulation process involves modifications of the current in the focusing coil and subsequent study of consistent patterns of the changes:

- in the angular velocity of the precession of the magnetic induction;

- in the Larmor radius of the magnetic induction;

- in the magnetic induction of the coil current.

\section{The research findings on the effect of an electromagnetic field on the ions of the water flow impurities}

Impurity ions that form a filtrate are chemically active. They are neutralized with external energy flows that perform the function of physical filters. An axially symmetric magnetic field changes the energy of the impurity ions' state, which leads to the ionization of impurities and increases the effectiveness of the magnetic system [9]. The difference in concentrations of cations and anions in the filtrate generates local electromagnetic fields [10]. Interaction of a permanent axially symmetric electromagnetic field with impurities causes the Larmor precession, which affects the mechanical trajectory of the charged particles around the vector of an external magnetic field. The aggregate of the Lorentz force and the Larmor force provides a helical path of the impurities, Fig. 1, whereas the total mass of impurities is focused into a paraboloid of revolution [11].

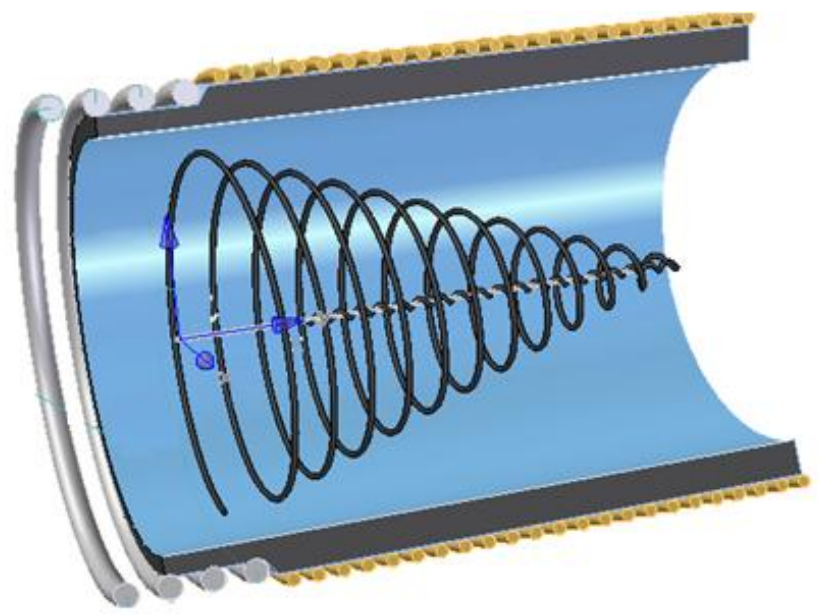

Fig. 1. A mechanical trajectory of impurities under the influence of the Lorentz force and the Larmor force combined

When the field intensity increases, the radius of the contaminants' circular motion (the Larmor radius) decreases and concentrates the impurities in the area of their removal from the general flow.

In case of axially symmetric longitudinal magnetic field [12] (Fig. 2), impurities' particles move along a helical path with a velocity of $v$.

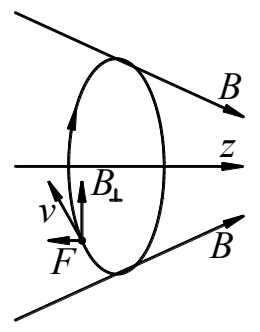

Fig. 2. The effects of the force vectors on a charged particle in an axially symmetric longitudinal magnetic field

This is predetermined by the sum of the two motion vectors - the circular one and the one along the line of force. The magnetic field intensity along the trajectory of 
a charged particle affects the radius of coils in a helix. The helix slope changes, i. e. there changes an angle formed by the trajectory and the directions of the lines of force. In the point where the lines of force of the magnetic field induction (B) converge, the Lorentz force $(F)$ is perpendicular to the plane of the Larmor circle. This force tries to push the particles from the area of a more intense field. Advantages of an axially symmetric longitudinal magnetic field include spinning of the impurities in the direction of the liquid flow motion and an increase in the time of the magnetic field effect on the impurity particles.

The device for magnetic treatment of a water flow consists of a tube of non-magnetic material and a magnetizing coil arranged around this tube.

The axially symmetric transverse magnetic field makes a charged particle oscillate [12]. Its mechanical trajectory bends in the flow under the action of the following forces:

- the axially symmetric transverse magnetic field (the Lorentz force);

- the electric field (the force of ion interaction).

The action of the electric field leads to damping of the oscillations. Advantages of the device include:

- twisting of the impurities transversely to the movement of the liquid flow;

- damping oscillations in the electric field, as well as;

- controlling ions of the impurities and subsequent removal of the latter.

A disadvantage is the dependence of the magnetic field intensity on the distance, which results in the restriction of the tube diameter.

In devices with an axially symmetric transverse magnetic field, magnets are placed in an aqueous medium flow (inside the device tube). The tube is used as part of the magnetic circuit and made of a magnetic material. An advantage is that the coefficient of the magnetic field use in the annular gap is about 0.8-1.0 RU [13]. A disadvantage is the need to protect the magnets from corrosion because of their location directly in the flow.

The experimental study is provided with a specially designed stand, Fig. 3. EMCD is an electromagnetic control device with a winding for focusing impurities in the flow, Fig. 3. The flow rate is determined with the help of an ultrasonic flow meter ULTRAHEAT 2WR783, Germany. Advantages of the flow meter are as follows:

- a special design of the measuring chamber that is not sensitive to axial asymmetric flows of liquid;

- the absence of damping linear parts and moving parts in the flow meter;

- a wide range of the flow rate measurement (from 1 to $200 \%$ of the rated consumption);

- a non-volatile power supply (a lithium battery with a service life of 5 years). The maximum pressure of the stand hydraulic system is $0.6 \mathrm{MPa}$.

Given the pressure, the tube diameter is between $0.07 \mathrm{~m}$ and $0.41 \mathrm{~m}$.

Water samples are taken from faucets F1-F3 according to GOST 24481-80. There emerges an orbital moment that increments the motion direction vector. It coincides with the vector of the torque acting on the impurity ions. As a result, the plane, in which there lie vectors of the orbital magnetic moment and induction of the external magnetic field, pivots through a certain angle. If this angle is determined from the mass and charge of the impurity ion, the angular frequency of precession is calculated as follows [11]:

$$
\omega_{\mathrm{L}}=\frac{\mathrm{e} \mid \cdot \mathrm{B}}{2 \cdot \mathrm{m}}
$$

where e is the charge of the particle, C; B is the magnetic induction, $\mathrm{T} ; \mathrm{m}$ is the mass of the charged particle, $\mathrm{kg}$.

In the relativistic case, the Larmor radius is found as follows [11]:

$$
\mathrm{R}=\frac{\mathrm{v} \cdot \mathrm{m}}{0.5 \cdot|\mathrm{e}| \cdot \mathrm{B}}
$$

where $v=1.5$ is the velocity of the liquid motion in the pipeline, $\mathrm{m} / \mathrm{s}$ [14].

Equation (2) shows that the Larmor radius is directly proportional to the mass and velocity of the particle and inversely proportional to the charge and magnetic induction in the electromagnetic control device. The magnetic induction is calculated as follows [11]:

$$
\mathrm{B}=\frac{\mu_{0} \cdot \mathrm{I} \cdot \mathrm{N}}{\mathrm{L}_{\mathrm{k}}},
$$

where $\mu_{0}=1.257 \cdot 10^{-6}$ is the magnetic constant, $\mathrm{H} / \mathrm{m} \mathrm{[15];}$ $\mathrm{I}$ is the current in the winding, $\mathrm{A} ; \mathrm{N}$ is the number of the winding turns, pcs; $\mathrm{L}_{\mathrm{k}}$ is the coil length, $\mathrm{m}$.

If we substitute equation (3) into equation (2), the dependence of the Larmor radius of a charged impurity particle on the coil current appears as

$$
\mathrm{R}=\frac{\mathrm{m} \cdot v \cdot \mathrm{L}_{\mathrm{k}}}{\mathrm{q} \cdot \mu_{0} \cdot \mu_{\mathrm{i}} \cdot \mathrm{I}}
$$

Analysis of the dependence of the Larmor radius of contaminants' motion is made by means of computer simulation. Simulation in LabView became possible due to the transfer of the above calculated purification system parameters in the machine view, Table 1 . The values of the focusing coil current are shown in Table 2.

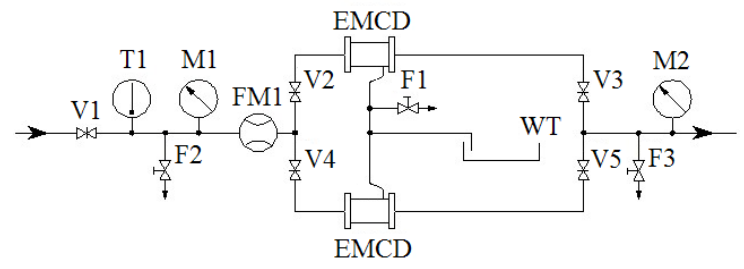

Fig. 3. A scheme of the experimental research stand on the electromagnetic purification, where EMCD is the electromagnetic control device, V1-V5 are valves, $\mathrm{T} 1$ is a bimetallic thermometer, M1-M2 are manometers, FM1 is an ultrasonic flow meter, WT is a water drain tank, F1-F3 are faucets

The values of Table 1 and Table 2 allow building the control panel of the virtual instrument of this study, Fig. 4.

The functional panel of the virtual instrument for studying the dependence of the Larmor radius of the charged impurity particles on the coil current is shown in Fig. 5. The function of "formulaic node" is used in analytical calculations. 
Table 1

Transfer of the symbolic parameters of the purification system in the machine constants

\begin{tabular}{|c|c|c|c|c|c|}
\hline Parameter & Symbolic view & Machine view & Dimension & Value & Source \\
\hline Mass of the contaminant charged particle & $\mathrm{m}$ & M & $\mathrm{kg}$ & $5.89 \times 10^{-26}$ & [15] \\
\hline Velocity of the charged particle in the flow & $v$ & $\mathrm{~V}$ & $\mathrm{~m} / \mathrm{s}$ & 1.5 & [15] \\
\hline Length of the particle focusing coil & $\mathrm{L}_{\mathrm{k}}$ & $\mathrm{L}_{\mathrm{k}}$ & $\mathrm{m}$ & 0.5 & Specified \\
\hline Elementary particle charge & $\mathrm{q}$ & Q & $\mathrm{C}$ & $1.6 \cdot 10^{-19}$ & [15] \\
\hline Magnetic constant & $\mu_{0}$ & M0 & $\mathrm{H} / \mathrm{m}$ & $1.257 \times 10^{-4}$ & [15] \\
\hline Magnetic permeability & $\mu_{\mathrm{i}}$ & $\mathrm{Mi}$ & RU & 0.999995 & [15] \\
\hline The Larmor radius & $\mathrm{R}$ & $\operatorname{Rg}$ & $\mathrm{m}$ & \multicolumn{2}{|c|}{ To be calculated } \\
\hline
\end{tabular}

Table 2

Values of the current in the impurity focusing coil

\begin{tabular}{|c|c|c|c|c|c|c|c|c|c|c|}
\hline № & 1 & 2 & 3 & 4 & 5 & 6 & 7 & 8 & 9 & 10 \\
\hline I, A & 0.03 & 0.06 & 0.09 & 0.12 & 0.15 & 0.18 & 0.21 & 0.24 & 0.27 & 0.30 \\
\hline
\end{tabular}

Length of

the coil, $\mathrm{Lk}$,

Current of the focusing coil,, $\mathrm{A} \quad \mathrm{m}$

\begin{tabular}{|c|c|}
\hline 0,03 & 0,05 \\
\hline 0,06 & \multirow{2}{*}{$\begin{array}{l}\text { The number of th } \\
\text { coil turns, N, pcs }\end{array}$} \\
\hline 70,09 & \\
\hline t) 0,12 & \\
\hline 6) 0,15 & $\sqrt{10}$ \\
\hline 6) 0,18 & \multirow{4}{*}{$\begin{array}{l}\text { Velocity of a chat } \\
\text { particle } \\
\text { in the flow, } \mathrm{V}, \mathrm{m} \\
\text { 1,50 }\end{array}$} \\
\hline 1) 0,21 & \\
\hline$\sqrt[5]{0,24}$ & \\
\hline$6 \longdiv { 0 , 2 7 }$ & \\
\hline \multicolumn{2}{|l|}{150} \\
\hline $\begin{array}{l}\text { Diameter of th } \\
\text { tube, } a=d r, m\end{array}$ & $\begin{array}{l}\text { Mass of the cont } \\
\text { charged particle, }\end{array}$ \\
\hline 0,07 & 5,89E-26 \\
\hline$\frac{1}{0}$ & Elementary \\
\hline 0,147 & \\
\hline a) 0,152 & $1,6 \mathrm{E}-19$ \\
\hline 1) 0,199 & Magnetic \\
\hline 150,237 & constant, M0 \\
\hline$\frac{n}{5} 0,241$ & $A_{1} 25656$ \\
\hline A 0,253 & $71,2566 \mathrm{E}-6$ \\
\hline 10,305 & \\
\hline$\frac{1}{\sqrt{3}} 0,406$ & \\
\hline
\end{tabular}

The number of the focusing Tables $1+2$ coil turns, N, pcs

\begin{tabular}{r|c|c|c|c}
\multicolumn{1}{r|}{$\mathbf{i}$} & $\mathbf{l , ~} \mathbf{A}$ & $\mathbf{R g}, \mathbf{M}$ & $\mathbf{a - d T ,} \mathbf{M}$ & $\mathbf{V p}, \mathbf{M}^{\wedge} \mathbf{3}$ \\
\hline \hline 1, & 0,030000 & 0,073179 & 0,070000 & 0,000275 \\
\hline 2, & 0,060000 & 0,036589 & 0,118000 & 0,000463 \\
\hline 3, & 0,090000 & 0,024393 & 0,147000 & 0,000577 \\
\hline 4, & 0,120000 & 0,018295 & 0,152000 & 0,000597 \\
\hline 5, & 0,150000 & 0,014636 & 0,199000 & 0,000781 \\
\hline 6, & 0,180000 & 0,012196 & 0,237000 & 0,000931 \\
\hline 7, & 0,210000 & 0,010454 & 0,241000 & 0,000946 \\
\hline 8, & 0,240000 & 0,009147 & 0,253000 & 0,000994 \\
\hline 9, & 0,270000 & 0,008131 & 0,305000 & 0,001198 \\
\hline
\end{tabular}

Mass of the contaminant charged particle, $\mathrm{m}, \mathrm{kg}$

7) $5,89 \mathrm{E}-26$

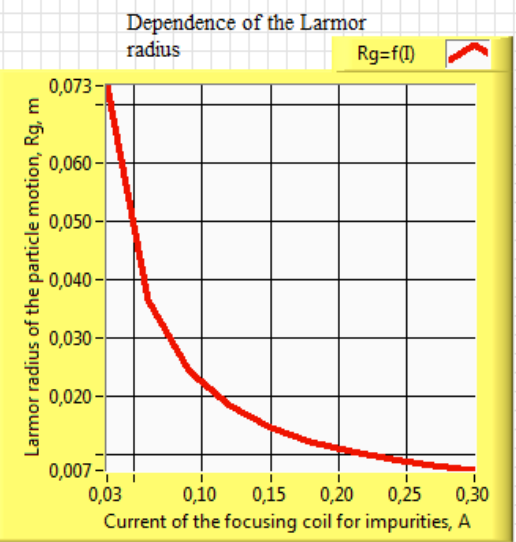

Dependence of the volume of the paraboloid of contaminants

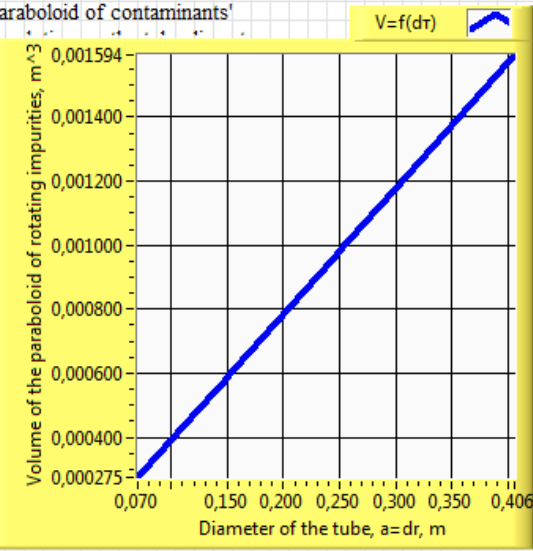

Fig. 4. The control panel of the virtual device of studying the dependence of the Larmor radius of contaminants' motion on the focusing coil current 


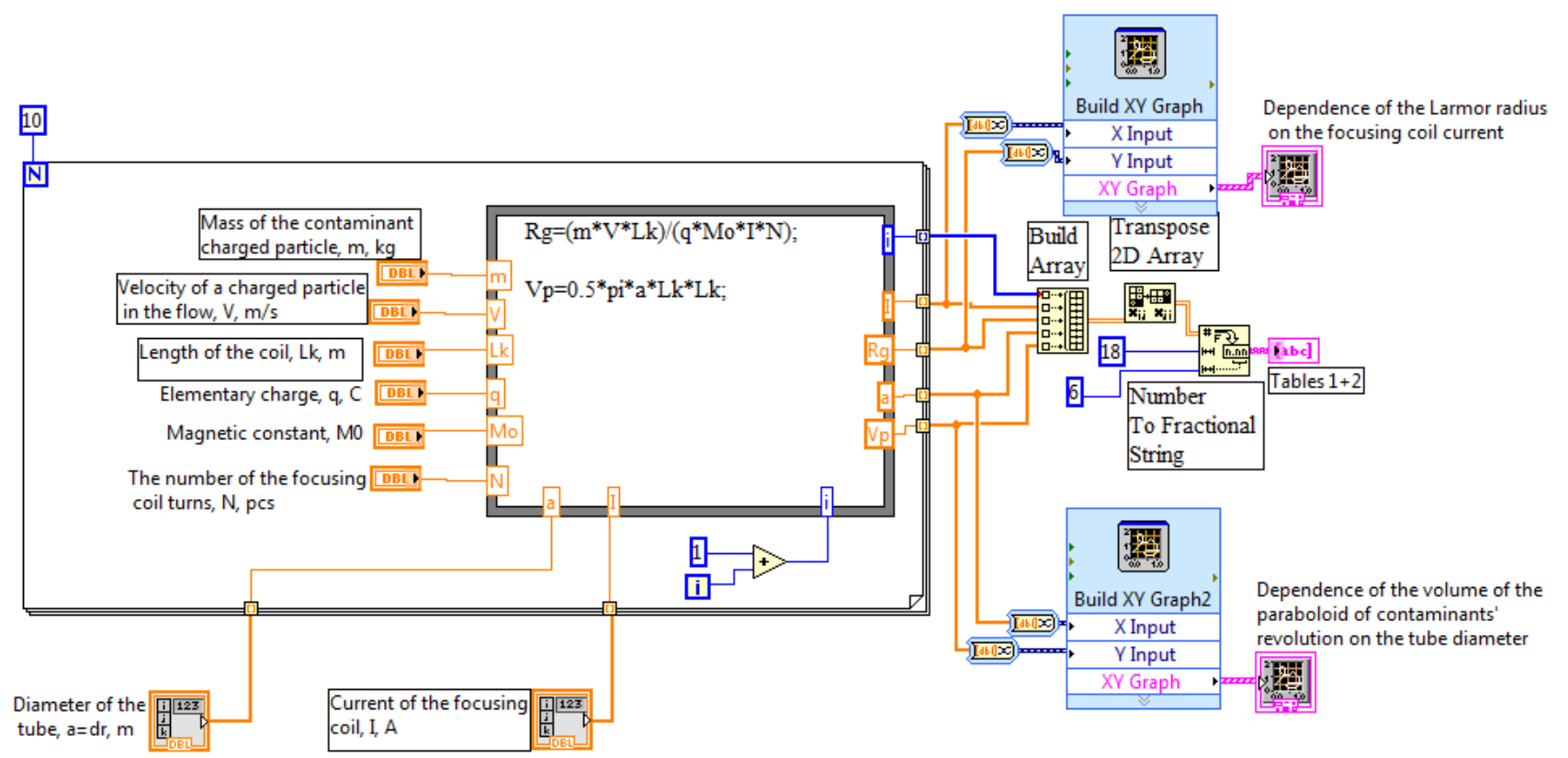

Fig. 5. The functional panel of the virtual device

Fig. 4, 5 show the tools of simulating the filtrate treatment process in $\mathrm{G}$ programming language. We used the original data of Table 1, 2 and set the following restrictions:

- the diameter of the paraboloid of impurity revolution is equal to or smaller than the diameter of the pipe for the main flow;

- the radius of the auxiliary branch pipes is equal to or larger than the Larmor radius of the contaminants' revolution.

\section{Discussion of the research findings on the effect of the electromagnetic field on the mechanical trajectory of impurities in the flow}

Fig. 6 illustrates the found dependence of the Larmor radius of the trajectories of charged particles on the current of the focusing coil for impurities in the flow.

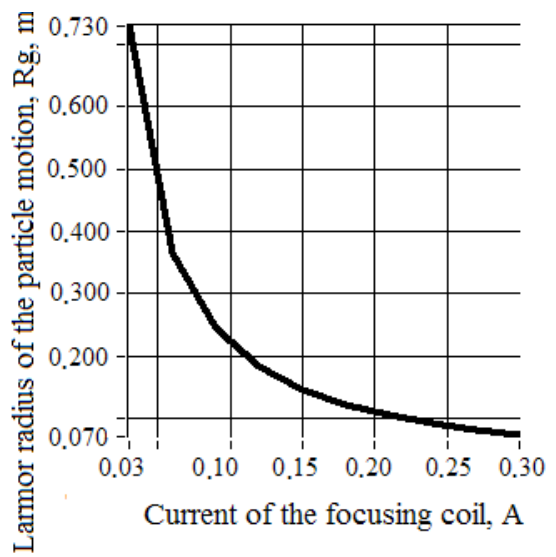

Fig. 6. The dependence of the Larmor radius of charged impurity particles on the focusing coil current

The dependence of the Larmor radius $\mathrm{R}$ of charged impurity particles on the current I in the focusing coil is a hyperbola with a parameter of $\mathrm{a}>0$ that has two typical parts. When the focusing coil current is between $0.03 \mathrm{~A}$ and $0.10 \mathrm{~A}$, the tangent of the curve angle is equal to $0.33 \mathrm{RU}$. An increase in the current from $0.10 \mathrm{~A}$ to $0.30 \mathrm{~A}$ reduces the tangent of the curve angle to $0.2 \mathrm{RU}$. This is because at low current in the focusing coil, between $30 \mathrm{~mA}$ and $100 \mathrm{~mA}$, contaminants pass a longer spiral path to removal from the main flow. When the coil currents exceed $100 \mathrm{~mA}$, the Larmor radius of the particles' becomes smaller, so the particles pass a shorter path to removal from the main flow. If the focusing coil current is between $0.03 \mathrm{~A}$ and $0.10 \mathrm{~A}$, the Larmor radius of the contaminants' motion decreases from $730 \mathrm{~mm}$ to $241 \mathrm{~mm}$. The selected auxiliary branch pipes have a radius larger than the Larmor radius. If the radius of contaminants' motion is $241 \mathrm{~mm}$, it is recommended to use tubes of $529 \times 6$ with an inner diameter of $517 \mathrm{~mm}$ or more. If the focusing coil current increases from $0.10 \mathrm{~A}$ to $0.30 \mathrm{~A}$, the Larmor radius of contaminants' motion decreases from $240 \mathrm{~mm}$ to $70 \mathrm{~mm}$. If the Larmor radius of impurities' motion is $70 \mathrm{~mm}$, it is recommended to use tubes of $159 \times 4.5$ with an internal diameter of $150 \mathrm{~mm}$ or more.

\section{Conclusions}

1. When the focusing coil currents are between $30 \mathrm{~mA}$ and $100 \mathrm{~mA}$, the contaminant passes a longer spiral path before its removal from the main flow. When the coil current exceeds $100 \mathrm{~mA}$, the Larmor radius of the particle shortens and the particle passes a shorter path to the removal from the main flow.

2. We have selected auxiliary branch pipes to remove contaminants from the main flow:

- if the focusing coil current increases from $0.03 \mathrm{~A}$ to $0.10 \mathrm{~A}$, the Larmor radius of the contaminants' motion decreases from $730 \mathrm{~mm}$ to $241 \mathrm{~mm}$; if the radius of contaminants' motion is $241 \mathrm{~mm}$, it is recommended to use tubes of $529 \times 6$ with an inner diameter of $517 \mathrm{~mm}$ or more; 
- if the focusing coil current increases from 0.10 A to 0.30 A, the Larmor radius of the contaminants' motion decreases from $240 \mathrm{~mm}$ to $70 \mathrm{~mm}$; if the Larmor radius of impurities' motion is $70 \mathrm{~mm}$, it is recommended to use tubes of $159 \times 4.5$ with an internal diameter of $150 \mathrm{~mm}$ or more.
3. Control of the mechanical trajectory of impurities by means of an electromagnetic device due to the aggregate of the Lorentz force and the Larmor force provides precession when the filtrate flows, focuses contaminants and removes them from the main flow.

\section{References}

1. Abdulhussain, A. A. Review on Landfill Leachate Treatments [Text] / A. A. Abbas, G. Jingsong, L. Z. Ping, P. Y. Ya, W. S. Al-Rekabi // American Journal of Applied Sciences. - 2009. - Vol. 6, Issue 4. - P. 672-684. doi: 10.3844/ajas.2009.672.684

2. Sathish, Effect of soaking of Phyllanthus emblica wood in drinking-water for purification [Text] / Sathish, S. Pandian, A. Amuthan // International Journal of Pharmacology and Clinical Sciences. - 2012. - Vol. 1, Issue 1. - P. 19-23.

3. Ambashta Ritu D. Water purification using magnetic assistance: A review [Text] / R. D. Ambashta, M. Sillanpää // Journal of Hazardous Materials. - 2010. - Vol. 180, Issues 1-3. - P. 38-49. doi: 10.1016/j.jhazmat.2010.04.105

4. Rouina, M., Effect of electromagnetic field on membrane fouling in reverse osmosis process [Text] / M. Rouina, H.-R. Kariminia, S. A. Mousavi, E. Shahryari // Desalination. - 2016. - Vol. 395. - P. 41-45. doi: 10.1016/j.desal.2016.05.009

5. Ibragimova, O. Blanket representation and expedient of disinfecting water using pulsing electromagnetic field [Text] / O. Ibragimova, A. Khalikov // IIUM Engineering Journal. - 2013. - Vol. 14, Issue 2. - P. 163-172.

6. Ali-Zade, P. Development of an electromagnetic hydrocyclone separator for purification of wastewater [Text] / P. Ali-Zade, O. Ustun, F. Vardarli, K. Sobolev // Water and Environment Journal. - 2008. - Vol. 22, Issues 1. - P. 11-16. doi: 10.1111/j.17476593.2007.00075.x

7. Russkikh, M. Influence of emr enf on plants lemna $\mathrm{m}$. and their use in the cleaning of sewage [Text] / M. Russkikh, O. Arefieva, L. Olshanskaia // Vestnik Saratovskoho gosudarstvennoho universiteta. - 2012. - Issue 1 (64). - P. 418-422.

8. Yamabhai, M., Diverse biological effects of electromagnetic-treated water [Text] / M. Yamabhai, S. Chumseng, K. Yoohat, W. Srila // Homeopathy. - 2014. - Vol. 103, Issues 3. - P. 186-192. doi: 10.1016/j.homp.2013.11.004

9. Artsymovich, L. Dvizhenie zariazhennykh chastits v elektricheskikh i magnitnykh poliakh [Text] / L. Artsymovich, S. Lukianov. Moscw: Nauka, 1978. - 224 p.

10. Kozlov, V. Larmorova pretsessiia [Text] / V. Kozlov // Laboratorniy praktikum po obshchey fizike. - Moscow: Moskovskij gosudarstvennyj universitet im. M. V. Lomonosova, 2006. - 14 p.

11. Raschet mahnitnoy induktsii kotushki [Electronic resource]. - Elektrotekhnika. - Available at: http://electe.blogspot.com/2011/07/ blog-post_27.html

12. Terentiev, O. Vykorystannia vnutrishnoi enerhii vodnoho seredovyshcha pry ochyshchenni yoho pid dieiu postiinoho mahnitnoho polia [Text] / O. Terentiev, O. Mozharovska // Visnyk NTUU “KPI”. Seriia: Hirnytstvo. - 2008. - Issue 17. - P. 154-158.

13. Varychev, O. Issledovanie apparatov dlia mahnitnoi obrabotki vody [Text] / O. Varychev. - Rostov na Donu: Lenivets, $1966 .-51$ p.

14. Bashta, T. Mashinostroitelnaia hidravlika [Text] / T. Bashta. - Moscow: Mashinostroenie, 1971. - 672 p.

15. Spiridonov, O. Fundamentalnye fizicheskie postoiannye [Text] / O. Spiridonov. - Moscow: Vysshaia shkola, 2001. - 238 p. 